\title{
Structure of the Ovary and the Differentiation of Follicular Epithelium in the Pig Louse, Haematopinus suis (Insecta: Phthiraptera)*
}

\author{
Monika ŻELAZOWSKA
}

Accepted January 25, 2005

\begin{abstract}
ŻELAZOWSKA M. 2005. Structure of the ovary and the differentiation of follicular epithelium in the pig louse, Haematopinus suis (Insecta: Phthiraptera). Folia biol. (Kraków) 53: 51-60.

The female reproductive system of the pig louse, Haematopinus suis (Insecta: Phthiraptera) is composed of paired ovaries, lateral oviducts, and a common oviduct that leads into a vagina. Clusters of mycetocytes (= cells filled with symbiotic organisms) are associated with lateral oviducts. Each ovary is composed of five loosely arranged ovarioles of the polytrophic-meroistic type. An individual ovariole is covered by a basal lamina and is composed of a terminal filament, germarium, and vitellarium. The terminal filament is composed of large, disc-shaped cells that are orientated perpendicularly to the long axis of the ovariole. The basal part of the terminal filament is separated from the germarium by a well-developed transverse septum. The germarium is short and filled with clusters of oogonial cells. In each cluster the cells are joined by intercellular bridges, filled with fusomal material. Within the cluster, only one cell, the future oocyte, enters the prophase of the first meiotic division; the other cells differentiate into nurse cells. The basal part of the germarium is filled with the somatic prefollicular cells. The boundary between the germarium and the vitellarium is not distinct. The vitellarium contains linearly arranged ovarian follicles in subsequent stages of oogenesis (previtellogenesis, vitellogenesis and choriogenesis). Each follicle consists of an oocyte and 7 nurse cells and is surrounded by follicular cells. During oogenesis the follicular cells diversify, so that ultimately, five morphologically distinct subpopulations of these cells can be distinguished: (1) cells in contact with the nurse cells, (2) anterior cells, (3) mainbody cells, (4) posterior cells, and (5) interfollicular cells. Interestingly, the follicular cells associated with the anterior part of the oocyte, i.e. located in space at the oocyte/nurse cell border (fold cells) are mitotically active throughout previtellogenesis. It might be suggested, in this context, that the separation of the oocyte from the nurse cell compartment is brought about by mitotic divisions, consequent multiplication and centripetal migration of these cells.
\end{abstract}

Key words: Oogenesis, follicular cells, ultrastructure, Phthiraptera.

Monika ŻELAZOWSKA, Department of Systematic Zoology, Institute of Zoology, Jagiellonian University, $R$. Ingardena 6, 30-060 Kraków, Poland.

E-mail: zawadz@zuk.iz.uj.edu.pl

Insect ovaries are composed of discrete units termed ovarioles. In the vast majority of species the ovarioles are differentiated into three regions: a terminal filament, germarium and vitellarium. Within the germarium mitotic divisions of germ cells take place. The vitellarium contains developing ovarian follicles in a linear arrangement. Traditionally, two basic categories of insect ovarioles are recognized, panoistic and meroistic (BRANDT 1874). In the panoistic ovarioles all germ cell mitoses in germaria are followed by complete cytokineses and all resulting oogonia are transformed into oocytes. As a result panoistic ovarioles lack specialized nurse cells (see below). In the germaria of meroistic ovarioles, incomplete divisions of germ cells ( $=$ differential oogonial mitoses) lead to the formation of germ cell clusters (= clones). Usually, one cell of each cluster differentiates into an oocyte, whereas the others become the nurse cells. Meroistic ovarioles are usually divided into two subtypes, polytrophic and the telotrophic ovarioles (GROSS 1903). In polytrophic ovarioles the nurse cells alternate with the oocytes in the vitellarium and consequently each oocyte is accompanied by its own group of nurse cells. The oocytes and the nurse cells are connected by specialized structures termed intercellular bridges or ring canals. In telotrophic ovarioles all nurse cells are retained in the germarium (forming a trophic chamber) and are joined to the oocytes in the vitel- 
larium by elongated cytoplasmic tubes termed the trophic cords. In both polytrophic and telotrophic ovarioles, the nurse cells load the oocytes with macromolecules (rRNA, mRNA) and organelles (mitochondria, endoplasmic reticulum cisternae, ribosomes) during the first phases of oogenesis (BÜNING 1994; BILIŃSKI 1998). In polytrophic ovarioles, the "flow of nurse cell cytoplasm" into the oocyte usually takes place during the terminal phase of oogenesis (GUILD et al. 1997; BILIŃSKI \& JAGLARZ 1999; ŻELAZOWSKA \& BILIŃSKI 2001). After termination of this process nurse cells degenerate. This process has not been observed in telotrophic ovarioles.

In both panoistic and meroistic ovarioles, the oocytes and/or the nurse cells are surrounded by somatic follicular cells (FCs) that originate from the prefollicular tissue. Usually, FCs are highly synthetically active during their whole lifetime. They are involved in several crucially important processes, e.g. the establishment of internal asymmetry of the oocyte (reviewed in GOVIND \& STEWARD 1991; RAY \& SCHÜPBACH 1996; ROTH 2001), vitellogenesis (TELFER et al. 1982) as well as formation of egg coverings (vitelline envelope and the chorion) (MARGARITIS 1985). In some insects, e.g. dipterans, hemipterans, bugs and bird lice, the FCs diversify during oogenesis into morphologically and physiologically distinct subpopulations that are responsible for the production of various eggshell regions (MARGARITIS 1985; OGORZALEK 1987; ZAWADZKA et al. 1997; DOBENS \& RAFTERY 2000; KUBRAKIEWICZ et al. 2003; PYKA-FOŚCIAK et al. 2003).

In this paper the results of histological and ultrastructural investigations of the ovary of Haematopinus suis are presented. Special attention has been paid to the differentiation and diversification of the FCs. The involvement of these cells in the formation of the eggshell has been described elsewhere (ZAWADZKA et al. 1997).

\section{Material and Methods}

The adult females of Haematopinus suis were collected from domestic pigs.

\section{Whole mount preparations}

The ovaries were dissected and fixed in $4 \%$ formaldehyde (freshly prepared from paraformaldehyde) in phosphate-buffered saline (PBS). The specimens were then rinsed in PBS, mounted on microscopic slides and examined under a Jenalumar (Carl Zeiss, Jena, Germany) microscope equipped with Nomarski interference contrast.
Light (LM) and transmission electron microscopy (TEM)

The ovaries were dissected and fixed in $2.5 \%$ glutaraldehyde in $0.1 \mathrm{M}$ phosphate buffer, $\mathrm{pH} 7.4$ at room temperature, rinsed and postfixed in $1 \%$ osmium tetroxide in the same buffer. After dehydration in a series of ethanol and acetone, the material was embedded in Epon 812 (Fullam Inc., Latham, NY, USA). Semithin sections $(0.5 \mu \mathrm{m})$ were stained with $1 \%$ methylene blue in $1 \%$ borax, and examined under a Jenalumar microscope. U1trathin sections $(90 \mathrm{~nm})$ were contrasted with uranyl acetate and lead citrate and examined under a Jeol 100 SX TEM at $80 \mathrm{kV}$.

\section{Scanning electron microscopy (SEM)}

The ovarioles were fixed as described for LM and TEM, dehydrated, and critical-point dried. The specimens were then mounted on holders covered with double-stick tape, coated with carbon and gold, and examined under a JSM 5410 scanning electron microscope at $25 \mathrm{kV}$.

\section{Fluorescence microscopy (FLM)}

For detection of filamentous actin the ovaries were dissected and fixed in 4\% formaldehyde (freshly prepared from paraformaldehyde) in PBS for $40 \mathrm{~min}$ at room temperature. The specimens were then rinsed in PBS and stained with rhodamine-conjugated phalloidin (Sigma Chemical Co., St Louis, MO, USA) in PBS $(1 \mu \mathrm{g} / \mathrm{ml})$ for $30 \mathrm{~min}$ at room temperature in the dark. Labeled ovaries were mounted on microscopic slides and examined with a Jenalumar epifluorescence microscope equipped with appropriate filters.

For detection of DNA the ovaries were dissected and fixed as described above. Then, the ovaries were rinsed with PBS and after dehydration in a graded ethanol series the material was infiltrated and embedded in acrylic resin (Histocryl, Agar, Stansted, UK). Semithin sections $(0.5 \mu \mathrm{m})$ were stained with $1 \mu \mathrm{g} / \mathrm{ml}$ of diamidino-2-phenylidole dihydrochloride (DAPI, Sigma) in PBS for $20 \mathrm{~min}$ in darkness. The sections were then rinsed three times with PBS and examined under a Jenalumar epifluorescence microscope equipped with appropriate filters.

\section{Results}

Architecture of the female reproductive system

The female reproductive system of the pig louse is composed of paired ovaries, lateral oviducts, 
and a common oviduct that leads into a vagina. Specific, paired structures referred to as ovarian mycetomes are in direct contact with the lateral oviducts. The mycetomes are composed of relatively large mononuclear cells, termed the mycetocytes. The cytoplasm of these cells is tightly packed with symbiotic microorganisms that are transmitted transovarially to the next generation. This process has been described in a previous paper (ŻELAZOWSKA \& BILIŃSKI 1999).

\section{Structure of the ovary}

Each of the two ovaries is composed of five loosely arranged ovarioles of the polytrophic-meroistic type. Ovarioles are surrounded by a basal lamina and consist of a terminal filament, germarium and vitellarium (Figs 1-3). The terminal filament is composed of large, disc-shaped cells that are orientated perpendicularly to the long axis of the ovariole (not shown). The cytoplasm of these cells contains numerous mitochondria, endoplasmic reticulum (ER) cisternae (Fig. 8A, B) and extensive bundles of microfilaments located in the circumferential region of the cell (Fig. 8B, asterisk). Staining with rhodamine-conjugated phalloidin also revealed the occurrence of microfilaments in these cells (Fig. 2B). The plasma membranes of neighboring terminal filament cells are equipped with interdigitating processes (Fig. 8A). The basal part of the terminal filament is separated from the germarium by a transverse septum (Fig. 8A).

The germaria of adults are short (Figs 1-3) and contain clusters of oogonial cells. All cells of the cluster are joined by intercellular bridges that are filled with fine granular fusomal material (= the fusome) (Fig. 8C). The rims of the bridges are lined with a layer of electron-dense material (Fig. 8C, arrows). Within the clusters, only one cell, the future oocyte, enters the prophase of the first meiotic division (not shown). The basal part of the germarium is often occupied by early previtellogenic ovarian follicles that are surrounded by somatic prefollicular cells (Figs 2A, B). The prefollicular cells are distributed mostly in the peripheral zone and basal part of the germarium. They are spindle-shaped and orientated perpendicularly to the long axis of the ovariole (Fig. 3). Their cytoplasm contains free ribosomes, elements of rough endoplasmic reticulum (RER) and mitochondria (Fig. 8C).

The vitellarium consists of linearly arranged ovarian follicles, in subsequent stages of oogenesis (Figs 1,2). Each developing follicle is composed of an oocyte and 7 nurse cells and is surrounded by follicular epithelium (Figs 2A, B). Development of terminal oocytes, i.e. those located at the base of the ovarioles, in direct contact with the oviduct is asynchronous. Only one of these is nearly mature (late vitellogenic or choriogenic) while the remaining ones are in previtellogenic stages. As a result the eggs are laid singly at certain time intervals. This asynchrony is associated with the type of the oviposition that in lice is not seasonal but takes place during the whole life time of the adult females.

The process of oogenesis in phthirapterans has previously been divided into five consecutive stages: previtellogenesis (stages 1-2), vitellogenesis (stages 3-4) and choriogenesis (stage 5) (BILIŃSKI \& JANKOWSKA 1987).

\section{Early previtellogenesis (stage 1)}

Early previtellogenic oocytes are cone-shaped. The nurse cells are relatively small and isodiametric (Figs 2A, B). FCs surround the entire ovarian follicle and are already diversified into three morphological subpopulations:

(1) cells covering the oocyte

(2) cells remaining in contact with the nurse cells

(3) interfollicular cells (compare Fig. 17)

At this stage FCs of all these subpopulations are mononuclear. FCs covering the oocyte (subpopulation 1) are columnar (Fig. 2A, B) and tightly adjoined. The apical parts of these cells are equipped with short microvilli that interdigitate with the microvilli of the oocyte (not shown).

FCs of the second subpopulation are stretched over the nurse cell compartment. Their bodies are located in the small spaces at the border of two adjacent nurse cells (Fig. 10). These cells form long protrusions that wedge in between the nurse cells (Fig. 10, arrow).

The interfollicular cells (subpopulation 3 ) form interfollicular stalks that individuate developing ovarian follicles (Figs 2A, B, arrows). They are relatively large, disc-shaped and arranged in two layers. In each layer the cells are orientated perpendicularly to the long axis of the ovariole (Figs 2A, B, arrows; Fig. 4, black arrow and Fig. 11). Interfollicular cells contain large nuclei with prominent nucleoli and numerous mitochondria. The plasma membranes of cells from adjacent layers form interdigitating protrusions (Fig. 11).

\section{Late previtellogenesis (stage 2)}

During this stage, the oocyte elongates and its volume considerably increases (Fig. 4).

At the onset of this stage the FCs covering the oocyte become binuclear and diversify into two subpopulations: 


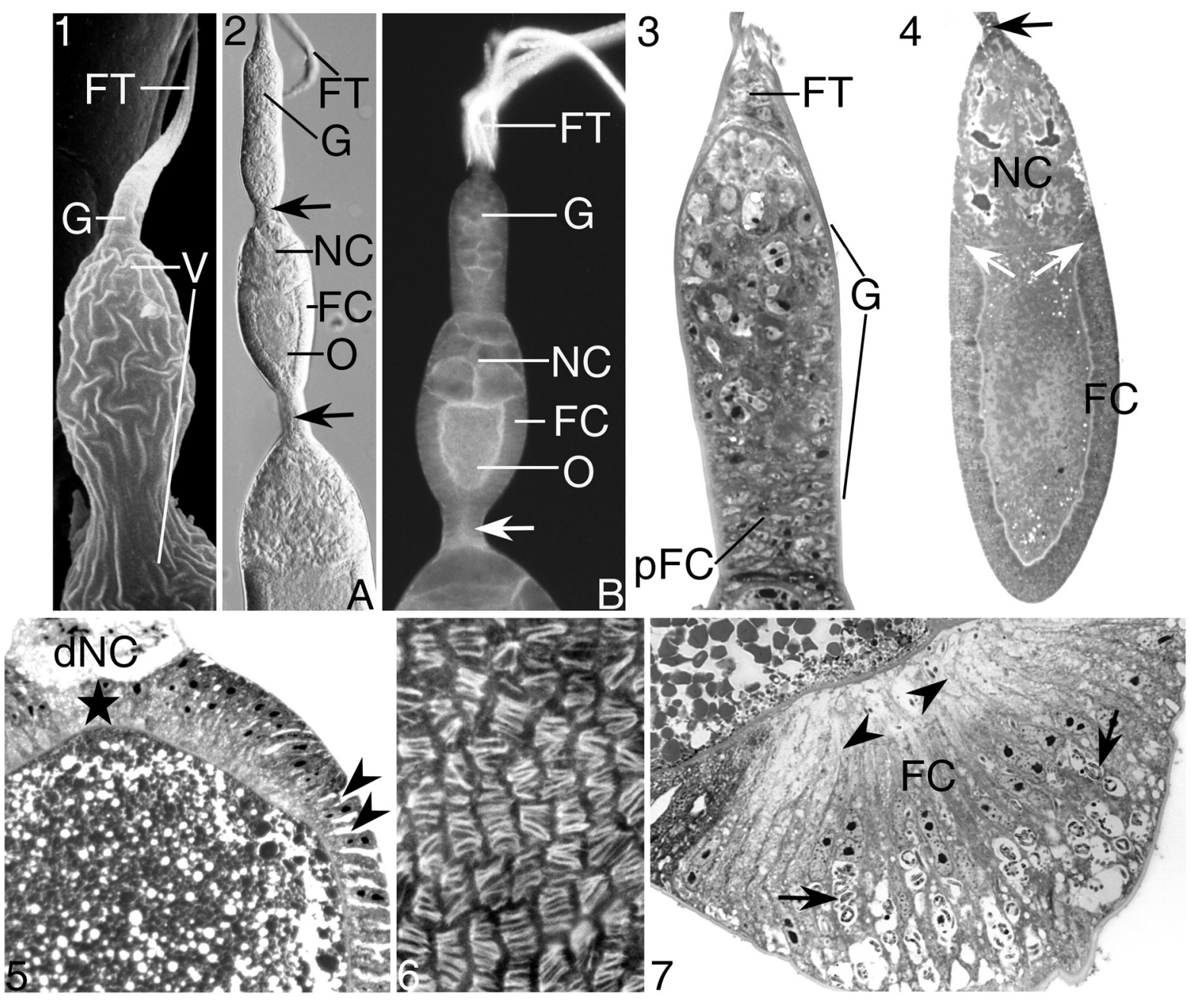

Figs 1-7. Fig. 1. The apical part of the ovariole. FT - terminal filament, G-germarium, V - vitellarium. SEM, x 4000. Fig. 2. Fragment of the ovariole. Terminal filament (FT), germarium (G), and a fragment of the vitellarium comprising early previtellogenic ovarian follicles, interfollicular cells (arrows), O - oocyte, NC - nurse cells, FC - follicular cells covering the oocyte. A. LM, Nomarski interference contrast, x 120. B. FLM, rhodamine-conjugated phalloidin, x 180. Fig. 3. The apical part of the ovariole. FT - terminal filament, $\mathrm{G}$ - germarium, pFC - prefollicular cells. LM, x 550. Fig. 4. Late previtellogenic ovarian follicle (stage 2). Interfollicular cells (black arrow), fold cells (white arrows), $\mathrm{FC}$ - cells covering lateral aspects and posterior pole of the oocyte, $\mathrm{NC}$ - nurse cells. LM, x 150. Fig. 5. Late vitellogenic ovarian follicle (stage 4). Anterior follicular cells (asterisk), intercellular spaces between the mainbody follicular cells (arrowheads), dNC - degenerating nurse cells. LM, $\mathrm{x} 200$. Fig. 6. Fragment of follicular epithelium (stage 3). Stress fibers in basal parts of cells covering lateral aspects of the oocyte. FLM, whole mount, rhodamine-conjugated phalloidin, x 400. Fig. 7. Posterior pole of late vitellogenic ovarian follicle (stage 4). FC - posterior follicular cells, the cell processes (arrowheads), symbiotic microorganisms (arrows). LM, x 450.

(1A) cells located in space at the oocyte/nurse cell border - fold cells

(1B) cells covering lateral aspects and the posterior pole of the oocyte (compare Fig. 17)

FCs of these subpopulations differ in shape and size. While the FCs covering the lateral aspects and the posterior pole of the oocyte are relatively small, the cells from subpopulation 1A strongly elongate and form a kind of fold that separates the ooplasm from the nurse cell compartment (Fig. 4, white arrows and Fig. 9A). These cells surround the funnel-shaped canal, referred to as the nutritive appendix, which ensures the contact of the oocyte and the nurse cells (not shown). Within the fold, characteristic roughly spherical cells in various stages of mitotic divisions have been frequently observed (Fig. 9B, arrow). The cytoplasm of these cells contains condensed chromatin, ER cisternae and vesicles, as well as mitochondria (Fig. 9B). Morphologically similar mitotic cells are also scattered between FCs covering the lateral aspects of the oocyte (Fig. 9C, arrow).

\section{Early vitellogenesis (stage 3 )}

During this stage the accumulation of reserve materials within the oocyte cytoplasm begins. The first lipid droplets and yolk spheres are gathered in the mid-length of the oocyte. FCs associated with the oocyte are still diversified into two subpopula- 

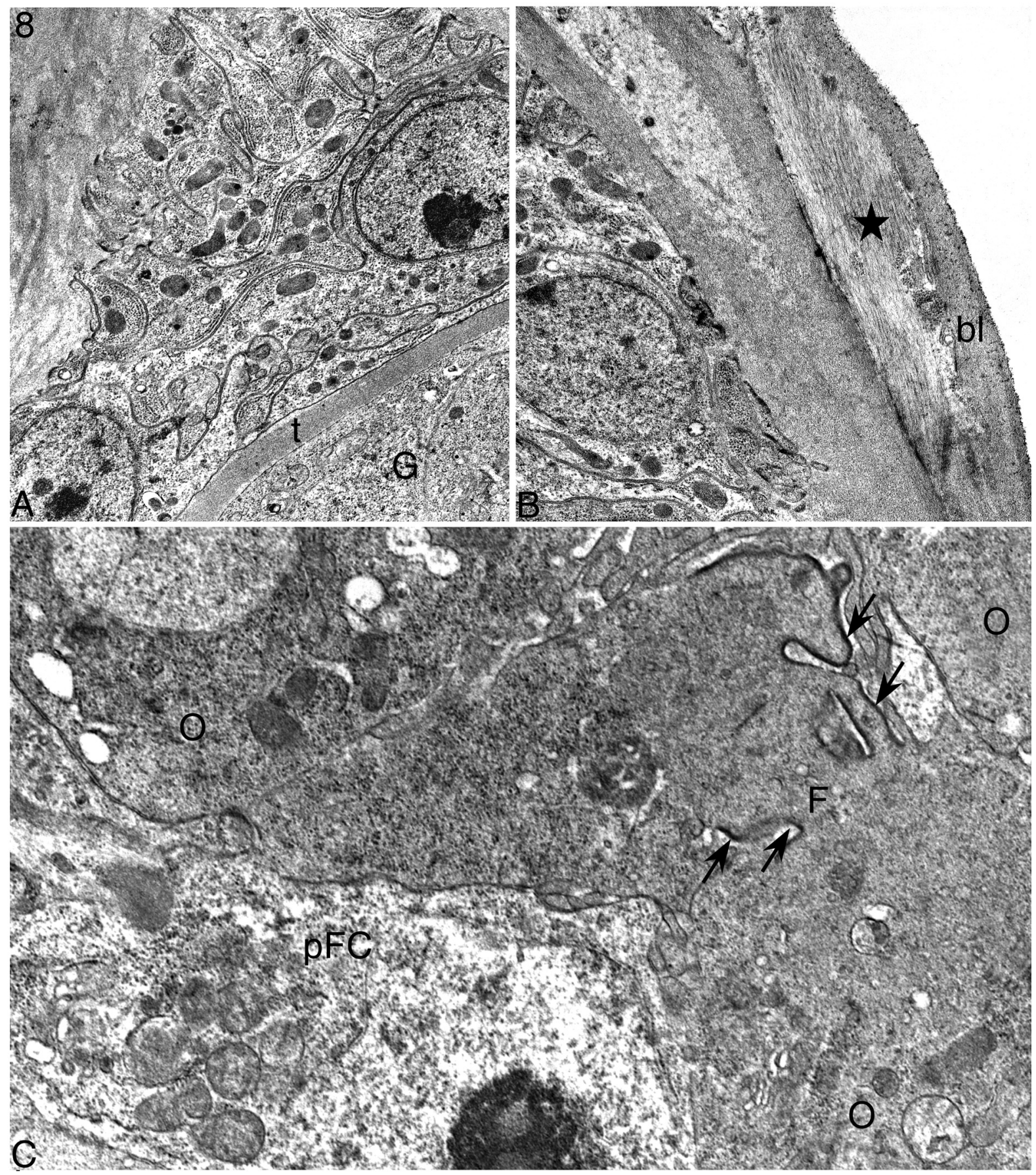

Fig. 8. A. Terminal filament cells (top), germarium $(\mathrm{G})$, transverse septum (t). TEM, x 14000; B. Terminal filament cells, bundle of microfilaments (asterisk) in the vicinity of a basal lamina (bl); tangential section. TEM, x 17 000; C. Germarium fragment of a cluster of oogonial cells. O - oogonial cells, $\mathrm{F}$ - fusomal material, the rims of an intercellular bridge (arrows), pFC - prefollicular cell. TEM, x 21000.

tions, however, FCs covering the lateral aspects and the posterior pole of the oocyte (subpopulation 1B) become more cuboid than in the previous stage. This process is accompanied by the development of prominent extracellular spaces that leads to the patency of the follicular epithelium (Fig. 5, arrowheads). Staining with rhodamineconjugated phalloidin revealed that the basal parts of FCs contain stress fibers orientated more or less perpendicularly to the anterior-posterior axis of the oocyte (Fig. 6).

\section{Stage 4 (late vitellogenesis)}

During this stage, oocyte volume significantly increases due to the accumulation of lipid droplets and yolk spheres (Fig. 5). Such dramatic growth is also a consequence of the transfer of nurse cell cy- 


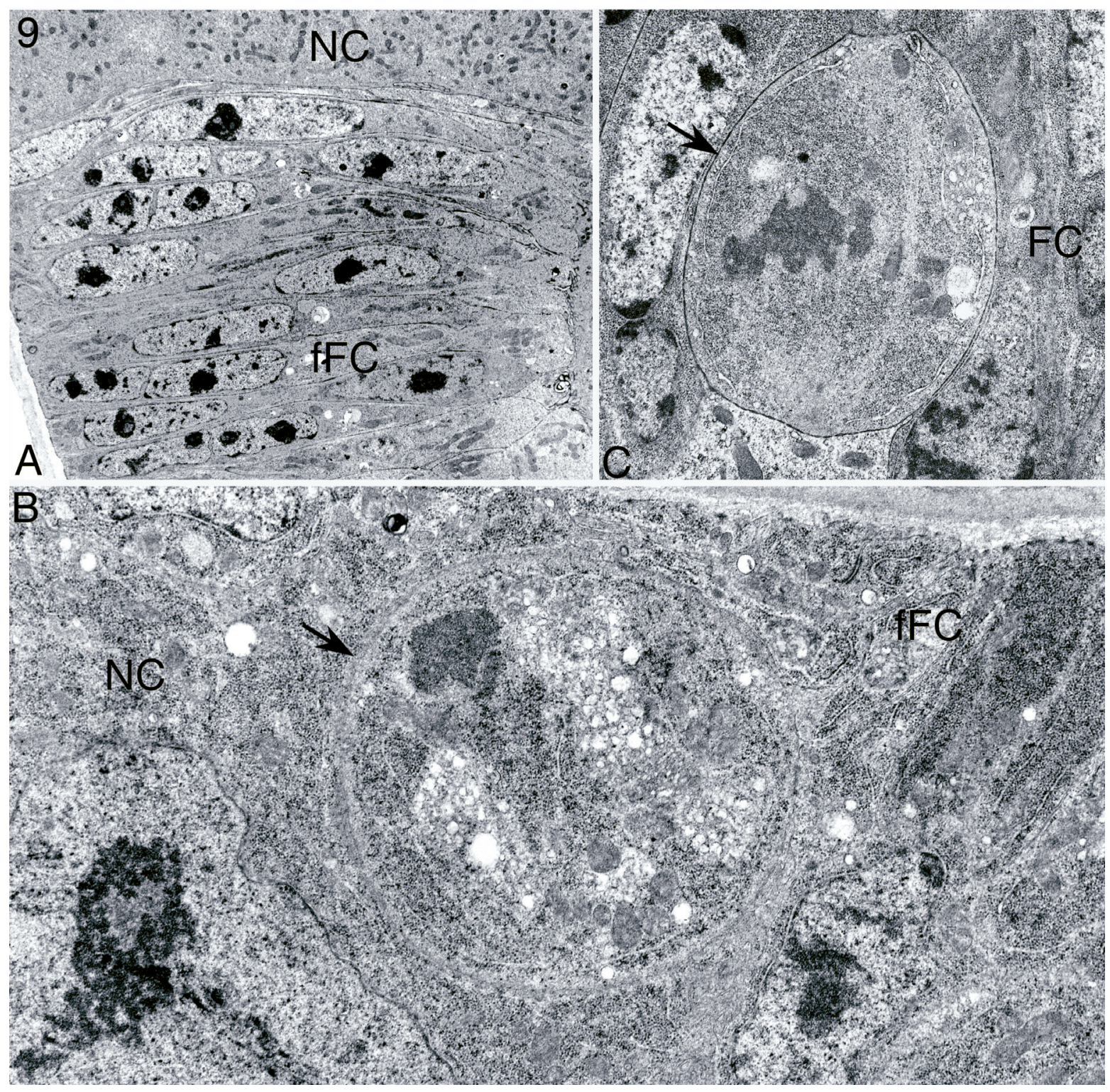

Fig. 9. Late previtellogenesis (stage 2). A and B. Fold cells (fFC), nurse cell (NC), dividing follicular cell (arrow). A. TEM, x 3400; B. TEM, x 15000; C. Follicular cells covering lateral aspects of the oocyte (FC), dividing follicular cell (arrow). TEM, x 9800.

toplasm into the ooplasm (described elsewhere, ŻELAZOWSKA \& BILIŃSKI 2001). After termination of the cytoplasm transfer the FCs located in the previous stages between the oocyte and the nurse cells (fold cells) cover the entire anterior oocyte pole separating the oocyte from the nurse cell compartment (Fig. 5, asterisk). The subsequent growth of these cells (anterior FCs) is accompanied by gradual degeneration of both the nurse cells and FCs remaining in contact with them (subpopulation 2) (Fig. 5).

Simultaneously, the FCs covering the posterior oocyte pole become clearly distinct from the FCs surrounding lateral aspects of the oocyte. The posterior FCs elongate, and become filled with numerous translucent vacuoles (Fig. 7). The apical parts of each of these cells form bundles of long processes that protrude towards the posterior oocyte pole (Figs 7, arrowheads and 16, arrows). These cells are involved in the transmission of symbiotic microorganisms (for the detailed description of this process see ŻELAZOWSKA \& BILIŃSKI 1999).

As a result of the processes described above the FCs covering the oocyte become diversified into three subpopulations:

(1A) cells covering the anterior oocyte pole - anterior FCs

(1B') cells associated with lateral aspects of the oocyte - mainbody FCs

(1B") cells surrounding the posterior oocyte pole - posterior Fcs 


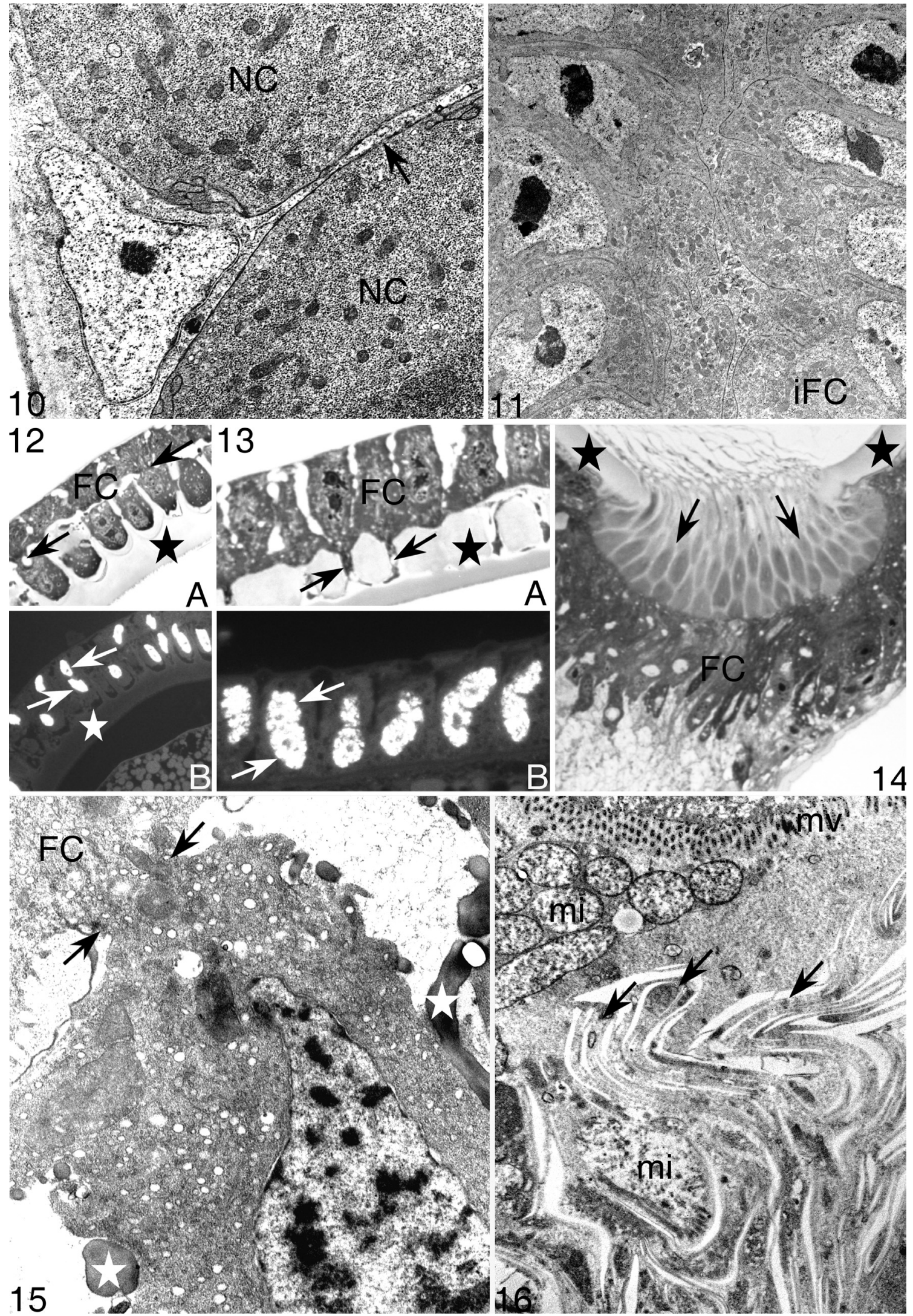

Figs 10-16. Fig. 10. Follicular cell remaining in contact with the nurse cells (NC), the process of the cell (arrow). TEM, x 12000. Fig. 11. Fragment of an interfollicular stalk, interfollicular cells (iFC). TEM, x 4700. Figs 12-16. Choriogenesis (stage 5). Fig. 12. Anterior follicular cells (FC). A. Cell processes are connected with the cell by means of narrow stalks (arrows), chorion (asterisk). LM, x 400 B. Cell nuclei (arrows), chorion (asterisk). FLM, DAPI, x 300. Fig. 13. Mainbody follicular cells (FC). A. Cell processes (arrows), chorion (asterisk). LM, x 600. B. Cell nuclei (arrows). FLM, DAPI, x 600. Fig. 14. Posterior follicular cells (FC). Bundles of processes (arrows), chorion (asterisks). LM, x 550. Fig. 15. Anterior follicular cell (FC). The stalk connecting the process with the cell (arrows), chorion (asterisks). TEM, x 10000. Fig. 16. Posterior follicular cells. Bundles of processes (arrows), oocyte microvilli (mv), symbiotic microorganisms (mi). TEM, x 5600. 


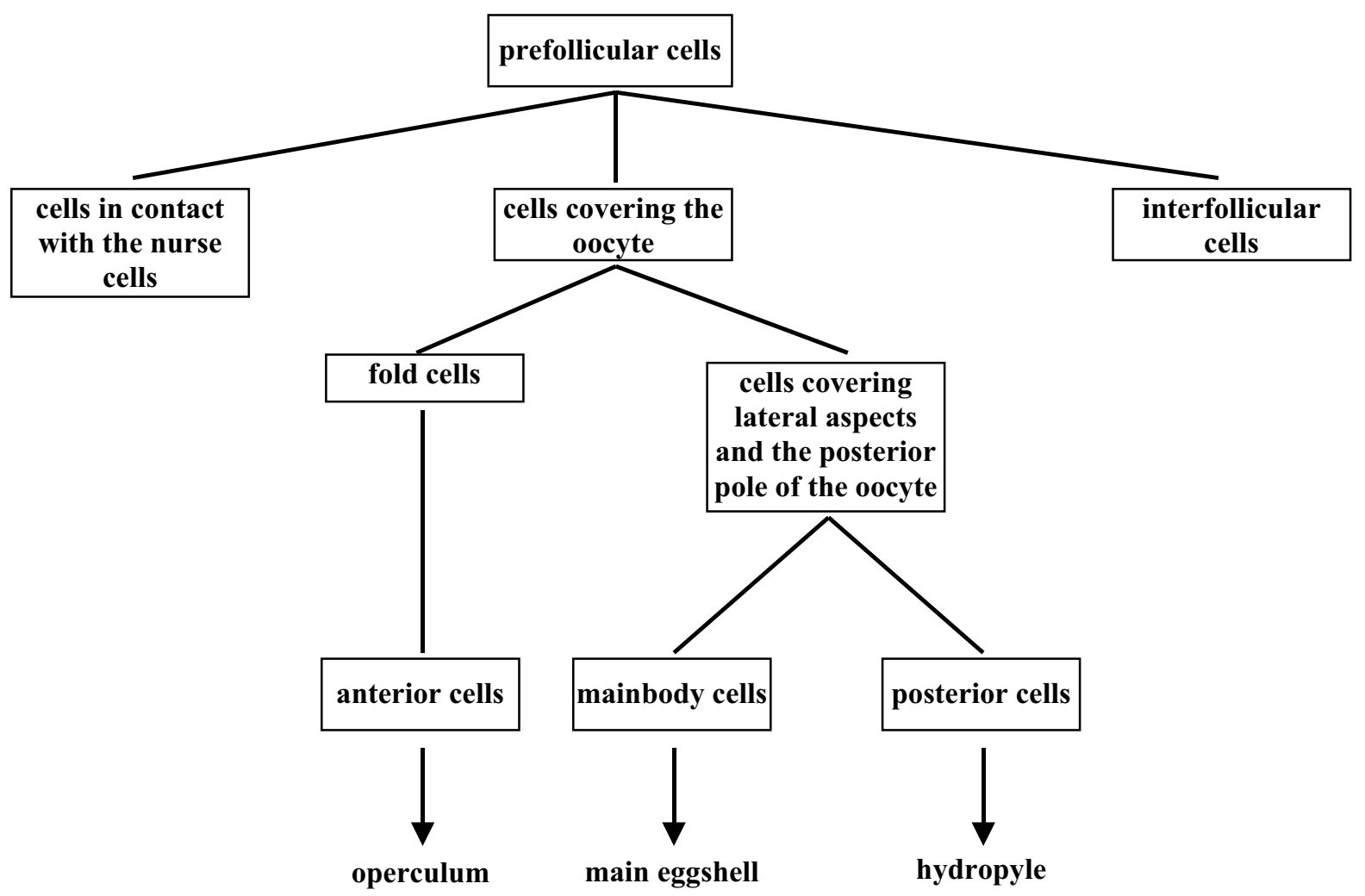

Fig. 17. Diversification of follicular cells in the pig louse. Subpopulations of cells are shown by boxes, their origin by lines, the type of chorionic structures produced is indicated by arrows.

\section{Choriogenesis (stage 5)}

During this stage of oogenesis, two envelopes (the vitelline envelope and the chorion) are deposited on the surface of the oocyte (Figs 12A, B, 13A, 14 , and 15, asterisks). The ooplasm of choriogenic oocytes is tightly packed with reserve materials such as yolk spheres and lipid droplets. The anterior part of the ovarian follicle contains degenerating nurse cells. The posterior part of the follicle is occupied by a mass of symbiotic microorganisms. They are located in the space between the posterior FCs and the oocyte, in close contact with the microvilli of the posterior oocyte pole plasma membrane (Fig. 16).

At the onset of choriogenesis the volume of all three subpopulations of FCs that surround the oocyte (1A, 1B', 1B') increases. Large nucleoli and aggregations of heterochromatin are clearly recognizable in their nuclei (Figs 12B and 13B). Their cytoplasm contains ER elements, free ribosomes as well as vacuoles filled with chorion precursors (Fig. 15). The apical parts of FCs produce different cellular processes (Figs 12A, 13A, 14). The anterior cells form broad processes that contain cell nuclei (Fig. 12A and Fig. 12B, arrows) and are connected with the cell by means of narrow stalks (Figs 12A and 15, arrows). The processes of mainbody cells are narrower (Fig. 13A, arrows) and their nuclei remain in the main body of a cell (Fig. $13 \mathrm{~A}$ and Fig. $13 \mathrm{~B}$, arrows). The apical parts of cells from the posterior subpopulation are equipped with bundles of long processes (Figs 14 and 16, arrows). These three subpopulations of FCs are engaged in the formation of basic elements of the eggshell, i.e. an operculum (anterior FCs - 1A, Figs 12 and 15), a main eggshell (mainbody FCs 1B', Fig. 13) and a hydropyle (posterior FCs 1B', Figs 14 and 16) (compare Fig. 17; for further details see ZAWADZKA et al. 1997). After the termination of chorion deposition the FCs degenerate.

\section{Discussion}

In insect ovaries, each oocyte in the vitellarium is surrounded by somatic FCs that form a singlelayered epithelium. A series of functions have been attributed to FCs. It is well documented that the follicular epithelium is involved in the process of yolk accumulation, vitellogenesis. In the fruit fly, the FCs synthesize yolk proteins (= vitellogenins) (BRENNAN et al. 1982), whereas in the moth, Hyalophora cecropia, they secrete macromolecules responsible for the adsorption of vitellogenins to the oocyte plasma membrane (TELFER et al. 1982). In stick insects (Phasmida), the FCs are en- 
gaged in the transfer of yolk proteins from the hemolymph towards the oocyte (FAUSTO et al. 1998). In all investigated species (TELFER et al. 1982; BILIŃSKI \& SZKLARZEWICZ 1987; OGORZAŁEK 1987) the shape of the FCs changes at the onset of vitellogenesis. This, in turn, leads to the patency of the epithelium and enables the endocytotic uptake of vitellogenins by the oocyte (HUEBNER \& INJEYAN 1980; TELFER et al. 1982; WATSON \& HUEBNER 1986; RAIKHEL \& DHADIALLA 1992). In H. suis, the gradual development of the patency coincides with the appearance of thick bundles of microfilaments, the stress fibers in the basal parts of the mainbody FCs. Similarly distributed microfilaments have also been described in the fruit fly (GUTZEIT 1990; GUTZEIT et al. 1993), the bug Dysdercus intermedius, and the honey bee Apis mellifera (FLEIG et al. 1991). According to GUTZEIT (1990) such microfilaments serve mechanical functions and increase the stiffness of the basal side of the cells and their adhesiveness to the basal lamina. They also play a role in the flattening of FCs during this stage of oogenesis. The results presented in this account reinforce this assumption.

The origin of FCs has been thoroughly investigated in the fruit fly, Drosophila melanogaster (MARGOLIS \& SPRADLING 1995). In this species each ovariole contains two somatic stem cells located at the border between regions $2 a$ and $2 b$ of the germarium. The divisions of these cells produce a population of prefollicular cells that diverges and gives rise to all FCs surrounding a syncytium of oocyte and nurse cells.

In some insects, e.g. dipterans, bugs and phthirapterans, during subsequent stages of oogenesis initially uniform FCs diversify into morphologically distinct subpopulations that, during choriogenesis, are responsible for the formation of various eggshell specializations. It has been shown that in the fruit fly, Drosophila melanogaster, this process is genetically regulated, and also plays a role in the establishment of embryonal axes (GOVIND \& STEWARD 1991; RAY \& SHÜPBACH 1996; ROTH 2001). In Drosophila as many as eight subpopulations of FCs arise: anterior polar cells, border cells, squamous/stretched cells, centripetal cells, mainbody cells, posterior terminal cells, posterior polar cells and interfollicular cells (MARGARITIS 1985). The first seven of these subpopulations of FCs encase the developing ovarian follicles. Interfollicular cells form stalks that individuate the follicles. These stalks are composed of five to seven oval-shaped cells arranged in a single stack. Interestingly, in the investigated species the arrangement of cells in interfollicular stalks is different - they form two tightly adjoining layers.

Among the subpopulations of FCs in the fruit fly ovaries at least two show the ability to migrate over the surface of germ cells or between them: the border cells and centripetal cells. In wild type ovaries, the border cells arise at the anterior end of the ovarian follicle. Subsequently, during stage 9, these cells undergo epithelial-mesenchymal transition and become invasive (MONTELL 2003). They surround the anterior polar cells (two spherical cells situated at the anterior pole of the follicle and connected with the interfollicular stalk) and actively migrate between the nurse cells towards the anterior oocyte pole. This migration involves large-scale rearrangement of the cytoskeleton and formation of elongated processes that penetrate between the nurse cells. During choriogenesis the border and polar cells are involved in the formation of the micropylar apparatus (MARGARITIS 1985; ZARANI \& MARGARITIS 1991). The centripetal cells arise between squamous/stretched cells and mainbody FCs. During stage 10B, after the termination of the transfer of nurse cell cytoplasm to the oocyte, these cells migrate centripetally and gradually penetrate between the oocyte and degenerating nurse cells. The leading edge of the centripetal cells comes to rest at the border cells. As a result, the entire anterior oocyte pole becomes covered with FCs. During choriogenesis the centripetal cells are responsible for the formation of the operculum (MARGARITIS 1985; ZARANI \& MARGARITIS 1991).

Migrating subpopulations of FCs seem to be characteristic only for higher dipterans (for further details see KUBRAKIEWICZ et al. 2003). Separation of the oocyte from the degenerating nurse cells and consequently the origin of the FCs that must cover the anterior oocyte pole before the deposition of the eggshell, have not been studied in detail in insects with polytrophic ovaries and remain practically obscure. In all phthirapterans, including the pig louse (BILIŃSKI \& JANKOWSKA 1987; ZAWADZKA et al. 1997), the FCs associated with the anterior oocyte pole are strongly elongated and form a kind of a fold. This fold surrounds the narrow cytoplasmic canal (= the nutritive appendix) responsible for the contact of the growing oocyte with synthetically active nurse cells. Interestingly, at least some of the fold cells divide mitotically. It might be suggested, in this context, that mitotic divisions, consequent multiplication of the fold cells and their centripetal migration, might be responsible for the final separation of the oocyte from the nurse cell compartment. Although no evidence has been found supporting active migration, the possibility that the fold cells migrate actively cannot be entirely ruled out. This hypothesis, however, needs further testing.

In the investigated species, the cells of the fold (= the anterior FCs) are responsible for the formation of the operculum during choriogenesis (ZAWADZKA 
et al. 1997). Thus, the anterior FCs of the pig louse functionally correspond to centripetal cells of the fruit fly.

\section{Acknowledgements}

The author wishes to thank to Prof. E. PYZA (Institute of Zoology, Jagiellonian University, Kraków, Poland) for electron microscopy facilities and Dr N. POŚPIECH (Department of Zoology and Ecology, Academy of Agriculture, Kraków, Poland) who collected the specimens of the pig louse. Skillful technical assistance from Mrs. W. JANKOWSKA and Mrs. B. SZYMAŃSKA is acknowledged.

\section{References}

BILIŃSKI S. M. 1998. Ovaries, oogenesis and insect phylogeny. Introductory remarks. Folia Histochem. Cytobiol. 36: $143-145$.

BILIŃSKI S. M., JAGLARZ M. K. 1999. Organization and possible functions of microtubule cytoskeleton in hymenopteran nurse cells. Cell Motil. Cytoskeleton 43: 213-220.

BILIŃSKI S. M., JANKOWSKA W. 1987. Oogenesis in the bird louse Eomenacanthus stramineus (Insecta, Mallophaga). I. General description and structure of the egg capsule. Zool. Jb. Anat. 116: 1-12.

BILIŃSKI S. M., SZKLARZEWICZ T. 1987. Ultrastructural modifications of the follicular epithelium accompanying the onset of vitellogenesis in the whirligig beetle, Gyrinus natator. Cell Tissue Res. 249: 209-214.

BRANDT A. 1874. Über die Eirohren der Blatta orientalis (Periplaneta). Mem. Acad. Imp. Sci. VIIme Ser. 21: 1-30.

BRENNAN M. D., WEINER A. J., GORALSKI T. J., MAHOWALD A. P. 1982. The follicle cells are the major site of vitellin synthesis in Drosophila melanogaster. Dev. Biol. 89: $225-236$

BÜNING J. 1994. The Insect Ovary. Ultrastructure, Previtelogenic Growth and Evolution. Chapman and Hall, London.

DOBENS L. L. , RAFTERY L. A. 2000. Integration of epithelial patterning and morphogenesis in Drosophila ovarian follicle cells. Dev. Dynamics 218: 80-93.

Fausto A. M., FAVA E., MAZzINI M. 1998. Confocal laser scanning microscopy of the follicular epithelium in ovarioles of the stick insect Carausius morosus. Cell Tissue Res. 293: 551-561.

Fleig R., Gutzeit H. O., EnGELs W. 1991. Structural organization of ovarian follicle cells in the cotton bug (Dysdercus intermedius) and the honeybee (Apis mellifera). Cell Tissue Res. 265: 297-305.

GOVIND S., STEWARD R. 1991. Dorsoventral pattern formation in Drosophila. Trends in Genetics 7: 119-125.

GROSS J. 1903. Untersuchungen über die Histologie des Insecten Ovariums. Zool. Jb. Abt. Morphol. 18: 71-186.

Guild G. M., Connelly P. S., Shaw M. K., Tilney L. G. 1997. Actin filament cables in Drosophila nurse cells are composed of modules that slide passively past one another during dumping. J. Cell Biol. 138: 783-797.

GUTZEIT H. O. 1990. The microfilament pattern in the somatic follicle cells of mid-vitellogenic ovarian follicles of Drosophila. Eur. J. Cell Biol. 53: 349-356.

Gutzeit H. O., SEYdLITZ-KurzBACH E., NEUSCHRÖER R. 1993. How Drosophila (Diptera: Drosophilidae) follicle become spatially organized and obtain their ovoid shape. Int. J. Insect Morphol. Embryol. 22: 335-347.

HUEBNER E., INJEYAN H. 1980. Follicle modulation during oocyte development in an insect. Formation and modification of septate and gap junctions. Dev. Biol. 83: 101-113.

KuBRAKIEWICZ J., JABŁOŃSKA A., MAZURKIEWICZ M., BILIŃSKI S. M. 2003. Differentiation and diversification of the follicular cells in flies: insight from the studies of the lower brachycerans' ovaries. Genesis 36: 214-224.

MARGARITIS L. H. 1985. Structure and the physiology of the eggshell. (In: Comprehensive Insect Physiology, Biochemistry and Pharmacology, vol. 1 Embryogenesis and Reproduction, G. A. Kerkut and L. I. Gilbert eds. Pergamon Press, Oxford).

MARGOLIS J., SPRADLING A. 1995. Identification and behavior of epithelial stem cells in the Drosophila ovary. Development 121: 3797-3807.

MONTELL D. J. 2003. Border-cell migration: the race is on. Nat. Rev. Mol. Cell Biol. 4: 13-24

OGORZAŁEK A. 1987. Inductive effect of oocyte nucleus on ovarian follicle morphogenesis in water bugs (Heteroptera). (In: Recent Advances in Insect Embryology in Japan and Poland, H. Ando and C. Jura eds. ISEBU, Tsukuba): 51-67.

PYKA-FoścIAK G., JANKOWSKA W., SZKLARZEWICZ T. 2003. Ultrastructural studies on the formation of egg envelopes in fulgoromorphans (Insecta, Hemiptera, Fulgoromorpha: Dictyopharidae). Folia biol. (Kraków) 51: 171-179.

RAIKHEL A. S., DHADIALLA T. S. 1992. Accumulation of yolk proteins in insect oocytes. Ann. Rev. Entomol. 37: 217-251.

RAY R. P., SCHÜPBACH T. 1996. Intercellular signalling and the polarization of body axes during Drosophila oogenesis. Genes Dev. 10: 1711-1723.

RoTH S. 2001. Coordinating germ line and soma. Curr. Biol. 11: $779-781$.

TELFER W. H., HuEBNER E., SMITH D. S. 1982. The cell biology of vitellogenic follicles in Hyalophora and Rhodnius. (In: Insect Ultrastructure, vol. 1, R. C. King and H. Akai eds. Plenum Press, New York).

WATSON A. J., HUEBnER E. 1986. Modulation of cytoskeletal organization during insect follicle cell morphogenesis. Tissue Cell 18: 741-752.

ZARANI F. E., MARGARITIS L. H. 1991. The eggshell of Drosophila melanogaster. VII. Formation of the micropylar canal and the role of the paracrystalline structure. Roux's Arch. Dev. Biol. 200: 95-103.

ZAWADZKA M., JANKOWSKA W., BILIŃSKI S. M. 1997. Egg shells of mallophagans and anoplurans (Insecta: Phthiraptera): morphogenesis of specialized regions and the relation to F-actin cytoskeleton of follicular cells. Tissue Cell 29: 665-673.

ŻELAZOWSKA M., BILIŃSKI S. M. 1999. Distribution and transmission of endosymbiotic microorganisms in the oocytes of the pig louse, Haematopinus suis (L.) (Insecta: Phthiraptera). Protoplasma 209: 207-213.

ŻELAZOWSKA M., BILIŃSKI S. M. 2001. Ultrastructure and function of nurse cells in phthirapterans. Possible function of ramified nurse cell nuclei in the cytoplasm transfer. AS\&D 30: $135-143$. 